\title{
Gastric adaptation to injury by repeated doses of aspirin strengthens mucosal defence against subsequent exposure to various strong irritants in
} rats

\author{
T Brzozowski, P C Konturek, S J Konturek, H Ernst, J Stachura, E G Hahn
}

\begin{abstract}
Gastric adaptation to injury during repeated doses of acetyl salicylic acid (ASA) is a well documented finding but it is not known whether this adaptation affects the tolerance of the mucosa to other strong irritants. Gastric adaptation was induced by repeated daily doses of acidified ASA $(100 \mathrm{mg} / \mathrm{kg}$ in $1.5 \mathrm{ml}$ of $0 \cdot 2 \mathrm{~N} \mathrm{HCl}$ ) given intragastrically (series $A$ rats). Control rats with an intact stomach were given daily intragastric vehicle only (1.5 ml of $0.2 \mathrm{~N} \mathrm{HCl}$ ) (series B). After full adaptation to ASA (5 days), rats were challenged again with acidified ASA or, for comparison, with strong irritants such as $100 \%$ ethanol, $200 \mathrm{mM}$ acidified taurocholate, or $25 \% \mathrm{NaCl}$ for 1 hour or with water immersion and restraint for 3.5 hours. The first dose of ASA produced numerous gastric lesions and deep histological necrosis accompanied by a fall in the gastric blood flow, negligible expression of epidermal growth factor (EGF) and transforming growth factor $\alpha$ (TGF $\alpha$ ) or their receptors, and no evidence of mucosal proliferation. As adaptation to ASA developed, however, the areas of gastric lesions were reduced by more than
\end{abstract} $80 \%$ and there was a noticeable decrease in deep necrosis, a partial restoration of gastric blood flow, an approximately fourfold increase in EGF expression (but not in TGF $\alpha$ ) and its receptors, and an appreciable increase in mucosal cell proliferation compared with vehicle treated rats. Increases in the mucosal expression of EGF receptors and the luminal content of EGF were also found in ASA adapted animals. In ASA adapted rats subsequently challenged with $100 \%$ ethanol, $200 \mathrm{mM}$ TC, $25 \% \mathrm{NaCl}$, or stress, the area of the gastric lesions and deep histological necrosis were appreciably reduced compared with values in vehicle treated rats. This increased mucosal tolerance to strong irritants was also accompanied by the return of the gastric blood flow towards control levels and further significant increases in the mucosal expression of EGF receptors and mucosal cell proliferation. Gastric adaptation to ASA enhances the mucosal resistance to injury by strong irritants probably as a result of the restoration of the gastric blood flow and increased cell proliferation that may result from increased mucosal expression of EGF and its receptors.

(Gut 1995; 37: 749-757)

Keywords: gastric adaptation, gastric blood flow, cytoprotection, epidermal growth factor.

Long term gastric adaptation develops in response to repeated exposure of the gastric mucosa to various irritants. ${ }^{12}$ This adaptation was originally shown in gastric mucosa exposed to non-steroidal anti-inflammatory drugs (NSAID) including acetyl salicylic acid (ASA) ${ }^{3-6}$ and indomethacin, ${ }^{7}$ necrotising substances, ${ }^{8-11}$ or stress ${ }^{12}$ but neither the mechanism of this adaptation nor its influence on gastric mucosal defence against the damage by necrotising substances has been explored.

ASA and related agents given for the first time in a single dose may cause widespread damage to the surface epithelium and deep haemorrhagic lesions. The pathogenesis of NSAID gastropathy is poorly understood but it has been attributed to the topical irritation of the mucosa associated with the inhibition of mucosal prostaglandin generation and vascular injury as a result of neutrophil activation and thrombi formation. ${ }^{13-16}$

We reported recently that with repeated daily doses of ASA, 1718 mucosal adaptation develops within three to four days and persists for about six days; there is increased mucosal tolerance to further insults by ASA without significant injury. Which factors or mechanisms are responsible for this long term adaptation and how the development of the adaptation could contribute to the integrity of the gastric mucosa and its defence against the injury by strong irritants remains unexplained.

This study was designed:

- To examine the role of gastric mucosal blood flow, mucosal expression of epidermal growth factor (EGF) and transforming growth factor $\alpha(T G F \alpha)$ and their receptors, and mucosal cell proliferation in the mechanism of gastric adaptation to ASA;

- To compare the injurious effects of strong irritants on the ASA adapted stomach and the unadapted, vehicle treated stomach; and - To assess the mechanisms responsible for the increased mucosal defence of the ASA adapted gastric mucosa against various strong irritants. 


\section{Methods}

PRODUCTION OF GASTRIC LESIONS AND INDUCTION OF GASTRIC ADAPTATION

Acute gastric lesions were induced by an intragastric application of acidified ASA in male Wistar rats weighing $180-220 \mathrm{~g}$. The animals were fasted overnight in individual cages but had free access to water. There were two series of rats, $A$ and $B$, each comprising 80 rats. Series A animals received intragastric ASA $(100 \mathrm{mg} / \mathrm{kg}$ dissolved in $1.5 \mathrm{ml}$ of $0.2 \mathrm{~N} \mathrm{HCl}$ daily) and series $\mathrm{B}$ animals were given intragastric vehicle only $(1.5 \mathrm{ml}$ of $0.2 \mathrm{~N} \mathrm{HCl}$ daily).

Gastric adaptation in series A rats was achieved by repeated intragastric administration of acidified ASA, daily for five consecutive days as described in detail previously. ${ }^{18}$ Briefly, one group of rats received acidified ASA at a dose of $100 \mathrm{mg} / \mathrm{kg}$ at $10.00 \mathrm{am}$ and was killed one hour later (day 0). Another group also received acidified ASA $(100 \mathrm{mg} / \mathrm{kg}$ ) at 10.00 am but one hour later was refed until $5.00 \mathrm{pm}$, fasted overnight, given acidified ASA the next day at $10.00 \mathrm{am}$, and killed one hour later (day 1). Other groups underwent the same schedule of refeeding and refasting for 2 , 3 , or 4 consecutive days (day 2, 3, and 4, respectively) after the first exposure to ASA and were then killed. Next day, after five repeated daily doses of acidified ASA, when the adaptation to ASA was fully developed, and after an 18 hour fast rats of series $A$ were divided into five groups (each consisting 8-10 animals) and challenged intragastrically with $1.5 \mathrm{ml}$ of one of the following: acidified ASA, $100 \%$ ethanol, $200 \mathrm{mM}$ taurocholate, or $25 \%$ $\mathrm{NaCl}$ and killed after one hour or underwent water immersion and restraint stress and were killed after 3.5 hours as described before. ${ }^{12}$ For comparison, unadapted, vehicle treated rats with an intact stomach (series B) treated intragastrically for four days with $1.5 \mathrm{ml}$ of saline were divided into five groups of 8-10 rats each and were challenged with the same ulcerogens as the rats in series $A$.

MEASUREMENT OF THE GASTRIC BLOOD FLOW One hour after each of the topical ulcerogens had been applied intragastrically or after 3.5 hours of stress, the rats were lightly anaesthetised with ether and the gastric blood flow was measured in the oxyntic gland area of the stomach by means of local $\mathrm{H}_{2}$ gas clearance technique using an electrolytic regional blood flow meter (Biomedical Science, Model RBF-2, Japan). The double needle electrodes were inserted through the serosa into the mucosa, one electrode was used for local generation of $\mathrm{H}_{2}$ gas and the other for the measurement of tissues $\mathrm{H}_{2}$. With this technique, the $\mathrm{H}_{2}$ generated by the electrode is carried away by the flowing blood and the polarographic current detector gives the decreasing tissue $\mathrm{H}_{2}$ as the clearance curve, which is then used to calculate absolute values of the blood flow $(\mathrm{ml} / 100 \mathrm{~g}$-min) in the tissue as described previously. ${ }^{19}$ The mucosal blood flow was measured in the oxyntic gland area of the stomach that did not show macroscopically visible mucosal lesions, and the mean value of three consecutive recordings was calculated and expressed as a percentage of the control values recorded in the oxyntic mucosa of the stomach in vehicle treated rats. The stomachs were then removed, opened along the greater curvature, and pinned open for macroscopic determination of the area and the number of gastric lesions by computerised planimetry (Morphomat 10, Carl Zeiss, Berlin, Germany) by two investigators unaware of the treatment given.

\section{DETERMINATION OF MUCOSAL GENERATION OF} PROSTAGLANDIN $\mathrm{E}_{2}$

In series $A$ and $B$ rats, mucosal biopsy samples of the oxyntic gland area (about $100 \mathrm{mg}$ ) were taken immediately after the animals had been killed to determine the mucosal generation of prostaglandin $\mathrm{E}_{2}$ by specific radioimmunoassay (RIA) as described previously. ${ }^{19}$ The mucosal sample was placed in preweighted Eppendorf vials and $1 \mathrm{ml}$ of Tris buffer ( $50 \mathrm{mM}, \mathrm{pH}$ 3.5) was added to each vial. The samples were finely minced (for about 15 seconds) with scissors, washed, and centrifuged for 10 seconds, and the pellet was resuspended in $1 \mathrm{ml}$ of Tris. Each sample was then incubated on a vortex mixer for 1 minute and centrifuged for 15 seconds. The pellet was weighed and the supernatant was transferred to a second Eppendorf vial containing indomethacin $(10 \mathrm{mM})$ and kept at $-20^{\circ} \mathrm{C}$ until RIA. Prostaglandin $\mathrm{E}_{2}$ was measured in duplicate using RIA kits (New England Nuclear, Munich, Germany). The capability of the mucosa to generate prostaglandin $\mathrm{E}_{2}$ was expressed in $\mathrm{ng} / \mathrm{g}$ wet tissue weight.

DETERMINATION OF MUCOSAL EXPRESSION OF EGF AND TGF $\alpha$ AND THE MUCOSAL CONTENT OF EGF

For the determination of the luminal concentration of EGF, the cardia and the pylorus were ligated (after the blood flow had been measured) and $1 \mathrm{ml}$ of cold saline was instilled into the stomach to wash out the gastric contents. Each sample was centrifuged: the supernatant was collected, neutralised with $0 \cdot 1 \mathrm{~N} \mathrm{Na}(\mathrm{OH})$ to $\mathrm{pH} 7 \cdot 0$, and frozen at $-20^{\circ} \mathrm{C}$ until EGF RIA. In series $\mathrm{A}$ and $\mathrm{B}$, the mucosal samples (about $100 \mathrm{mg}$ ) were excised from the oxyntic gland area of the stomach for determination of the mucosal EGF content by RIA. ${ }^{18}$ The tissue samples were immediately weighed, homogenised in ice cold $0.32 \mathrm{M}$ Tris- $\mathrm{HCl}$ buffer, and centrifuged: the supernatant was collected and frozen at $-20^{\circ} \mathrm{C}$ until EGF radioimmunoassay. The EGF antiserum (gift of Dr H Gregory, ICI, Alderly Park, UK), raised in rabbits against human EGF was used at a final dilution of 1:210000 and this antiserum recognised equally rat and human EGF. Iodinated ([3-125I] iodotyrosyl) peptide and rat EGF were calibration standards (Amersham, UK). The detection limit of the assay was 
$0.01 \mathrm{nmol} / 1$. The intrassay and interassay precision were about $12 \%$ and $10 \%$, respectively.

MUCOSAL HISTOLOGY AND EXPRESSION OF EGF AND TGF $\alpha$ AND THEIR RECEPTOR

In some experiments, standardised strips incorporating the total width of stomachs were fixed in $10 \%$ buffered formalin and paraffin sections were stained with haematoxylin and eosin $(H \& \mathrm{E})$ for histological evaluation. A Nikon microscope equipped with microplan II digital image system was used for the quantitative histological examination (morphometry) of the sections. Coded specimens of mucosa stained with $\mathrm{H} \& \mathrm{E}$ were evaluated quantitatively under $500 \times$ magnification in blinded conditions. The disrupted surface of the mucosal strips denuded of epithelium, the deep necrotic lesions penetrating the mucosa, and the strip length with regeneration of the surface epithelium cells were measured and expressed as a percentage of the total. Coded specimens of mucosa stained with $\mathrm{H} \& \mathrm{E}$ were evaluated quantitatively under $500 \times$ magnification under blinded conditions. In addition, serial sections of paraffin embedded blocks were dewaxed, rehydrated, slides pretreated with citrate buffer ( $\mathrm{pH} 6)$ in a microwave oven $(3 \times 5 \mathrm{~min})$, and immunostained with specific monoclonal antibodies against EGF (1:40, GFO.1， Oncogene), TGF $\alpha$ (1:20, GF10

TABLE I Mean area of gastric lesions, prostaglandin $E_{2}$ $\left(P G E_{2}\right)$ generation, and gastric blood flow ( $\left.G B F\right)$ (expressed as percentage of the control value in the mucosa treated with vehicle) after the first (day 0) administration of acidified aspirin ( $A S A)(100 \mathrm{mg} / \mathrm{kg})$ and $A S A$ given at the same dose for next four days. Results are mean (SEM) for $8-10$ rats

\begin{tabular}{|c|c|c|c|}
\hline & $\begin{array}{l}\text { Lesion area } \\
\left(\mathrm{mm}^{2}\right)\end{array}$ & $\begin{array}{l}P G E_{2} \\
(n g / g)\end{array}$ & $\begin{array}{l}G B F \\
(\%)\end{array}$ \\
\hline $\begin{array}{l}\text { Vehicle (control) } \\
\text { Acidified ASA }\end{array}$ & - & $220(13)$ & 100 \\
\hline $\begin{array}{l}\text { Day } 0 \\
\text { Day } 1 \\
\text { Day } 2 \\
\text { Day } 3 \\
\text { Day } 4\end{array}$ & $\begin{array}{l}59 \cdot 6(8.4) \\
28 \cdot 3(5 \cdot 2)^{\star} \\
12 \cdot 7(4 \cdot 3)^{\star} \\
8.5(3 \cdot 7)^{\star} \\
5 \cdot 2(1 \cdot 8)^{\star}\end{array}$ & $\begin{array}{l}23(4) \\
17(3) \\
12(2) \\
13(3) \\
10(1)\end{array}$ & $\begin{array}{l}41(5) \\
65(8) \dagger \\
68(9) \dagger \\
75(12) \dagger \\
79(14) \dagger\end{array}$ \\
\hline
\end{tabular}

^Indicates a significant decrease in the area of gastric lesion below the value recorded with ASA given at day $0 .+$ Indicates a significant increase above the value of GBF obtained with ASA given at day 0 .
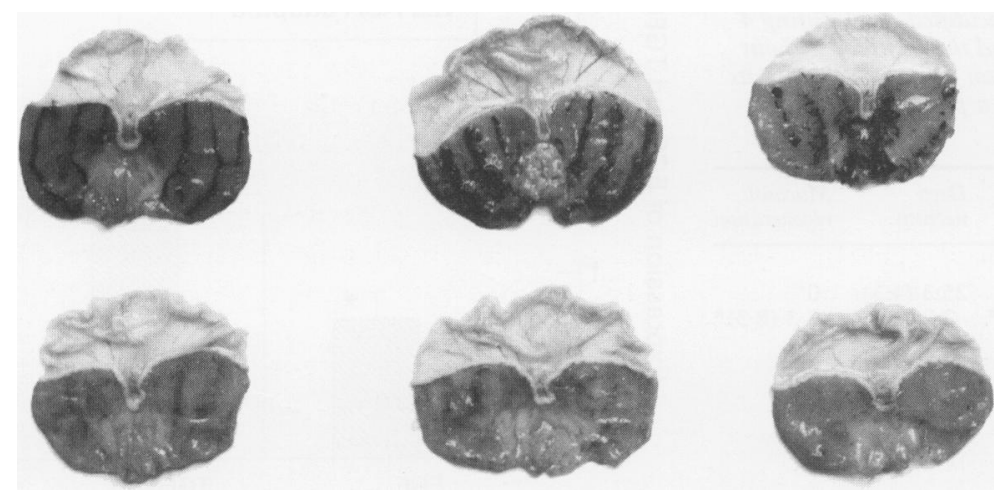

Figure 1: Typical macroscopic appearance of the stomach of rats after the first challenge (upper level) with acidified ASA (on the left), $100 \%$ ethanol (in the middle) or water immersion and restraint stress (on the right) in the unadapted animals. The lower level shows the stomach after the challenge with the acidified ASA (on the left), 100\% ethanol (in the middle), or stress (on the right) in rats adapted to repeated administration of acidified $A S A$. Note that the lesions in ASA adapted stomach were small and scattered mostly in the oxyntic gland area.
Oncogene), and EGF receptors (1:40, Sigma Chemical Co, St Louis, MO, USA) using the $\mathrm{ABC}$ method (ABC Kit, Oncogene) in accordance with methods described elsewhere. ${ }^{20}$

The sections were graded according to the intensity of cytoplasmic staining for EGF and TGF $\alpha$ by examination of 300 consecutive cells: coded specimens were independently assessed by two observers. The intensity of staining was assessed according to different regions of the gland (top, neck, and base) and was graded from 0 to III $(0=$ no staining, I $+=$ weak staining, II $+=$ moderately positive staining (cytoplasm positive but other details also visible), and densely stained as described elsewhere).${ }^{21} \mathrm{~A}$ mean intensity per section was calculated. Negative control sections were processed immunohistochemically after replacing the primary antibody with phosphate buffered saline or an irrelevant monoclonal antibody and positive control sections from pancreatic carcinoma (TGF $\alpha$ ), oesophageal carcinoma (EGFr) or submandibular gland (EGF) showed grade III labelling of EGF or TGF $\alpha)$.

\section{STATISTICAL ANALYSIS}

Results are presented as mean (SEM). Statistical analysis was done using non-parametric Mann-Whitney $U$ test and Friedman two way analysis of variance with a $p$ value of less than 0.05 being considered significant.

\section{Results}

GASTRIC DAMAGE INDUCED BY ASA AND DEVELOPMENT OF THE ADAPTATION TO ASA Acidified ASA, given orally for the first time (once), produced an increase in gastric erosions at a dose of $100 \mathrm{mg} / \mathrm{kg}$ that reached a mean area of about $60 \mathrm{~mm}^{2}$ (Table I). The area of gastric lesions was already significantly decreased the next day after the rechallenge with acidified ASA. After the next 4 days of ASA rechallenge, a marked decrease in the area of macroscopic gastric lesions was observed, indicating that full adaptation to acidified ASA had been achieved (Fig 1).

Gastric blood flow, which in the intact, vehicle treated stomach averaged 49 (7) $\mathrm{ml} / \mathrm{min}$ per $100 \mathrm{~g}$, was significantly decreased by about $60 \%$ after the first exposure to ASA (Table I). Then, after rechallenge with ASA (day 1), it tended to return to control values over the next four consecutive exposures to ASA (Table I). Mucosal generation of prostaglandin $\mathrm{E}_{2}$ in the vehicle treated mucosa averaged about 220 (13) $\mathrm{ng} / \mathrm{g}$ of wet tissue: the single exposure to acidified ASA reduced the mucosal generation of prostaglandin $\mathrm{E}_{2}$ by about $90 \%$ (Table I). The suppression of prostaglandin $\mathrm{E}_{2}$ generation persisted during all successive days of ASA treatment.

In the rats with an intact, unadapted stomach, intragastric acidified ASA $(100 \mathrm{mg} / \mathrm{kg}$ in $0.2 \mathrm{~N} \mathrm{HCl}$ ), $100 \%$ ethanol, $200 \mathrm{mM} \mathrm{TC}, 25 \%$ $\mathrm{NaCl}$, or exposure to 3.5 hours of stress resulted in the formation of gastric mucosal 


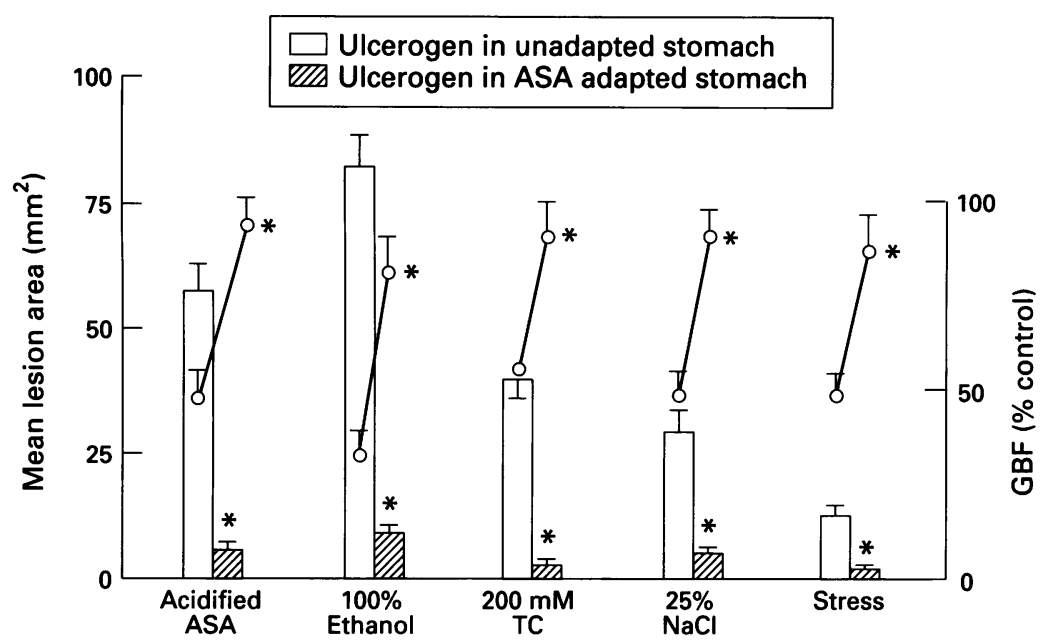

Figure 2: Mean (SEM) of gastric lesions and gastric blood flow (expressed as a percentage of the control value) in rat stomach adapted to ASA and in the intact unadapted stomach in response to acidified $\mathrm{ASA}, 100 \%$ ethanol, $200 \mathrm{mM}$ taurocholate, $25 \% \mathrm{NaCl}$, or water immersion and restraint stress. Mean values of $8-10$ rats. ${ }^{\star}$ Indicates significant change compared with the values recorded in the intact unadapted stomach.

lesions with mean areas of $58(6), 82(8), 40$ (5), 32 (4), or 10 (1) $\mathrm{mm}^{2}$ respectively (Fig 2). This was accompanied by a severe reduction in the gastric blood flow compared with the value obtained in gastric mucosa treated only with vehicle. In rats with ASA adaptation subsequently challenged on day 5 with acidified ASA $(100 \mathrm{mg} / \mathrm{kg}), 100 \%$ ethanol, $200 \mathrm{mM}$ TC, $25 \% \mathrm{NaCl}$, or stress, the areas of gastric lesions were reduced by $95 \%, 88 \%, 92 \%$, $93 \%$, or $90 \%$ respectively compared with respective values obtained in vehicle treated, unadapted control rats exposed to the same irritants. This reduction in the formation of acute gastric lesions in ASA adapted rats exposed to the irritants was accompanied by a significant rise in the gastric blood flow compared with that observed after each irritant in unadapted animals.

\section{HISTOLOGICAL FINDINGS}

Single exposure to acidified ASA resulted in hyperaemia of the gastric wall with acutely inflamed and oedematous submucosa. In the

TABLE II Quantitative histology of gastric mucosa after first exposure (day 0) to acidified $A S A(100 \mathrm{mg} / \mathrm{kg})$ and after four subsequent exposures to acidified ASA during 4 day's treatment with that agent and then with or without challenge with strong irritants. Mean (SEM) of 8-10 rats per group. Results are expressed as a percentage of the mucosal strip length

\begin{tabular}{lccl}
\hline & $\begin{array}{l}\text { Denuded } \\
\text { surface }\end{array}$ & $\begin{array}{l}\text { Deep } \\
\text { necrosis }\end{array}$ & $\begin{array}{l}\text { Mucosal } \\
\text { regeneration }\end{array}$ \\
\hline ASA: & & & \\
Day 0 & $45(6 \cdot 5)$ & $25 \cdot 3(4 \cdot 3)$ & 0 \\
Day 4 & $5 \cdot 8(1 \cdot 2)^{\star}$ & $2 \cdot 8(0 \cdot 4)^{\star}$ & $47 \cdot 3(8 \cdot 3)^{\star}$ \\
Irritant in unadapted stomach: & & \\
100\% Ethanol & $58 \cdot 2(7 \cdot 4)$ & $34 \cdot 4(6 \cdot 5)$ & 0 \\
$200 \mathrm{mM}$ taurocholate & $33 \cdot 5(6 \cdot 5)$ & $28 \cdot 8(3 \cdot 8)$ & 0 \\
25\% NaCl & $24 \cdot 8(3 \cdot 8)$ & $19 \cdot 5(2 \cdot 5)$ & 0 \\
ASA & $46 \cdot 6(5 \cdot 5)$ & $27 \cdot 4(4 \cdot 1)$ & 0 \\
WRS & $39 \cdot 1(4 \cdot 2)$ & $14 \cdot 2(2 \cdot 2)$ & 0 \\
Irritant in ASA adapted stomach: & & \\
100\% Ethanol & $5 \cdot 4(1 \cdot 2)^{\star}$ & $3 \cdot 9(0 \cdot 8)^{\star}$ & $38 \cdot 8(4 \cdot 2)^{\star}$ \\
$200 \mathrm{mM}$ taurocholate & $4 \cdot 2(0 \cdot 9)^{\star}$ & $2 \cdot 5(0 \cdot 6)^{\star}$ & $43 \cdot 7(6 \cdot 9)^{\star}$ \\
$25 \% \mathrm{NaCl}$ & $2 \cdot 8(0 \cdot 7)^{\star}$ & $1 \cdot 2(0 \cdot 3)^{\star}$ & $52 \cdot 2(9 \cdot 3)^{\star}$ \\
ASA & $5 \cdot 9(1 \cdot 5)^{\star}$ & $2 \cdot 5(0 \cdot 7)^{\star}$ & $42 \cdot 5(7 \cdot 5)^{\star}$ \\
WRS & $2 \cdot 7(0 \cdot 8)^{\star}$ & $1 \cdot 8(0 \cdot 5)^{\star}$ & $37 \cdot 9(3 \cdot 8)^{\star}$ \\
\hline
\end{tabular}

*Significant change compared with value obtained after first exposure to ASA. WRS=water restraint stress. gastric mucosa of rats exposed to ASA, the deep necrotic lesions occupied about $25 \%$ of the mucosal strip length (Table II). About $45 \%$ of the mucosa was, however, denuded of the surface epithelium in these rats and no regeneration of gastric mucosa was observed. In contrast, the gastric mucosa of rats adapted to ASA treatment showed remarkable regenerative changes, with elongation of the neck and foveolar areas lined with cuboidal regenerative epithelium. In the submucosa, the inflammatory infiltrate was mostly composed of polymorphonuclear and mononuclear cells. The macroscopic injury was considerably reduced only about $5 \%$ of the mucosa was denuded of surface epithelium and $4 \%$ of the mucosal length was involved in deep necrotic lesions.

In unadapted rats with an intact stomach, single insults of acidified ASA, $100 \%$ ethanol, $200 \mathrm{mM}$ TC, $25 \% \mathrm{NaCl}$, or stress meant that deep mucosal necrosis occupied about $27 \%$, $34 \%, 28 \%, 19 \%$, or $14 \%$ of mucosal strip length, respectively, and the lack of regenerative changes was noticed in these animals. In contrast, rats adapted to ASA and challenged with $100 \%$ ethanol, $200 \mathrm{mM}$ TC, $25 \% \mathrm{NaCl}$, acidified ASA, or stress, showed a significant reduction in the deep necrosis associated with the increase in mucosal regeneration compared with changes observed in unadapted rats exposed to each of the irritants (Table II).

\section{MUCOSAL EXPRESSION OF EGF AND TGF $\alpha$ AND} THEIR RECEPTORS AND LUMINAL AND MUCOSAL CONTENTS OF EGF

As shown in Figure 3, the expression of EGF, which was negligible in the intact, vehicle treated mucosa (staining intensity about $0 \cdot 18$ $(0.05)$ ), was increased in the ASA adapted stomach - approximately fourfold mainly at the neck area of gastric glands and threefold at the gland base (Figs 4, 5, and 6). The expression of TGF $\alpha$ in the vehicle treated, unadapted mucosa was relatively higher than that of EGF, with staining intensity averaging about 1.5

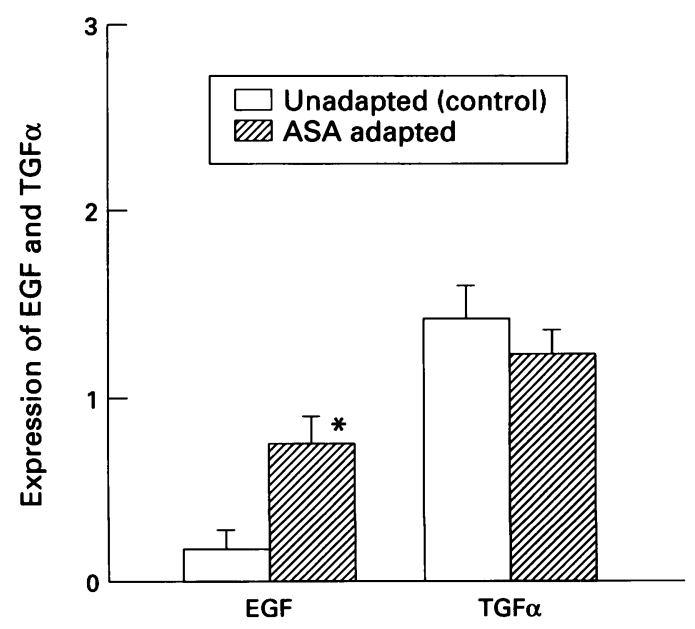

Figure 3: Expression of epidermal growth factor (EGF) (in arbitrary units from $0=$ no $E G F$ staining to $3=$ maximal staining) in the gastric mucosa adapted to ASA and in the mucosa of intact, vehicle treated stomach at the neck of the gastric glands. Mean (SEM) of 5 rats. ${ }^{\star}$ Indicates a significant increase above the control value in unadapted rats. 


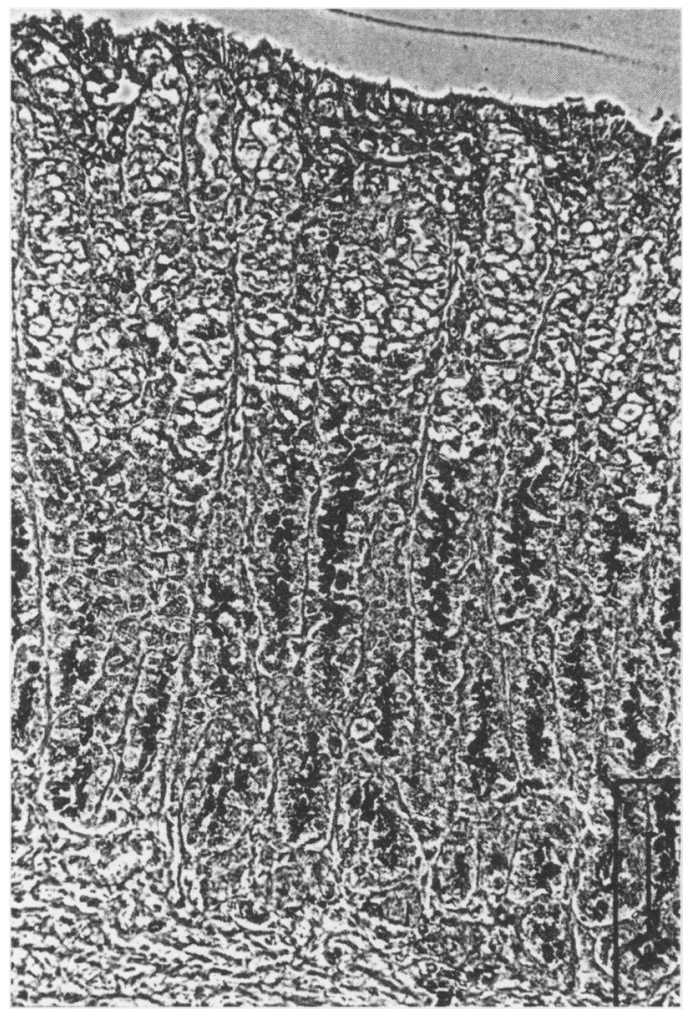

Figure 4: Gastric mucosa adapted to ASA. Prominent apical immunoreactivity for epidermal growth factor in the base and the neck regions of gastric glands (original magnification $\times 63$ ).

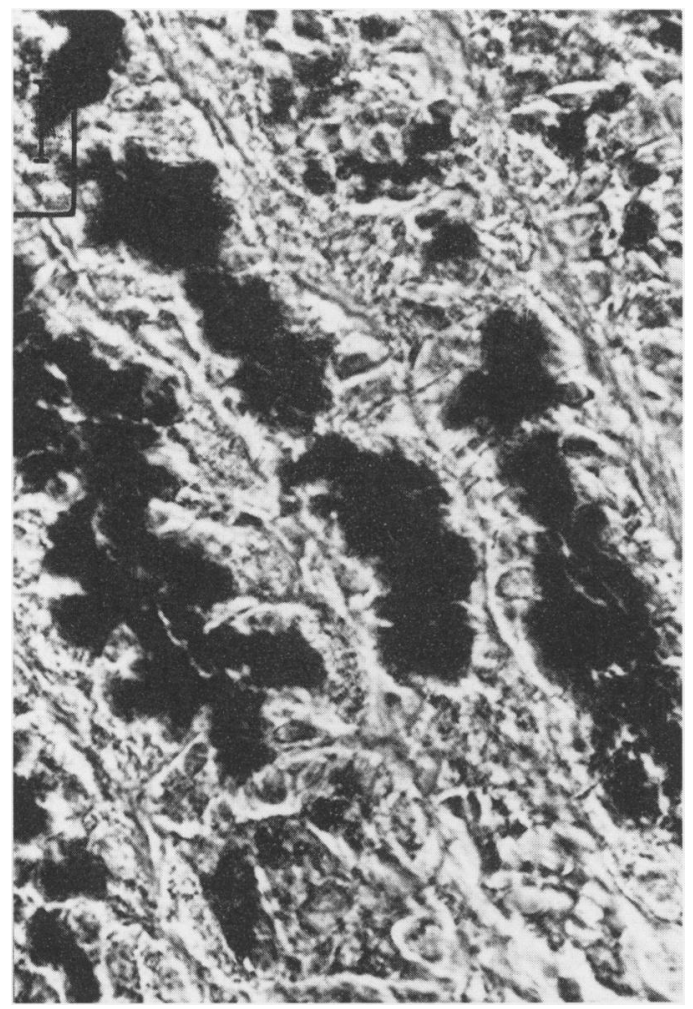

Figure 5: Prominent staining for epidermal growth factor in the lumen and apical part of the neck region of the gland in the stomach of rats adapted to ASA (original magnification $\times 250$ ).

$(0 \cdot 2)$ but this was not significantly changed upon the adaptation of mucosa to ASA (see Fig 3).

In the vehicle treated gastric mucosa, EGF receptor (EGFr) was expressed in some neck cells, mainly at their luminal plasma membranes, and in some single parietal cells

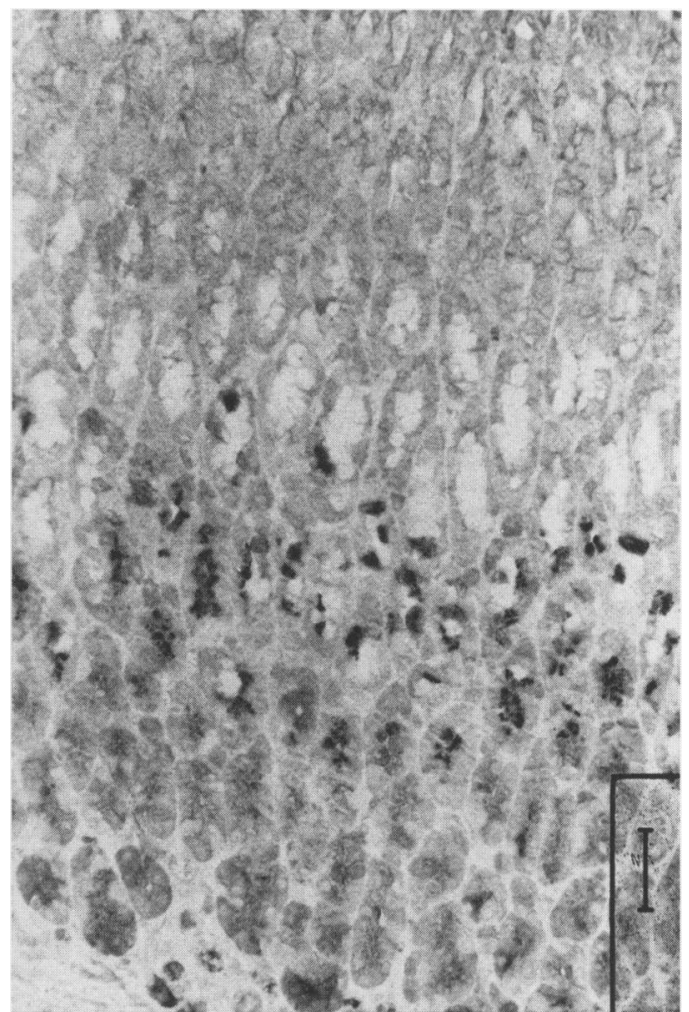

Figure 6: Vehicle treated rats. Weak staining for epidermal growth factor observed only in the neck region of the gastric glands (original magnification $\times 63$ ).

(Fig 7). After first exposure to acidified ASA, the expression of EGFr was diminished or absent in the area of deep necrotic lesions, while in non-necrotic mucosa the expression of EGFr was not significantly affected compared with that in the intact gastric mucosa (Table III). After repeat ASA insults, a significant increase in EGFr expression was observed in non-necrotic mucosa (Fig 8). In some surface epithelium cells, especially in regenerating mucosa with elongated foveolae and neck region, the expression was seen in both foveolar and neck cells. In these areas of regenerative mucosa, increases in the expression of EGFr in the neck region and the deeper areas of oxyntic mucosa were also observed. The expression of EGFr was diminished or absent in the areas of deep necrotic lesions in unadapted rats challenged with $100 \%$ ethanol, $200 \mathrm{mM} \mathrm{TC}$, or $25 \% \mathrm{NaCl}$. In contrast, the gastric mucosa of rats adapted to ASA and then challenged with $100 \%$ ethanol, $200 \mathrm{mM}$ TC, or $25 \% \mathrm{NaCl}$ showed enhancement in expression of EGFr similar to that in rats adapted to ASA and challenged with ASA and other irritants, especially in areas with strong regeneration of the mucosal surface area.

Table III shows the immunoreactivity of EGF in the gastric mucosa and in gastric juice in rats adapted to repeated ASA insults with or without the challenge with various strong irritants. The single exposure to ASA failed to affect significantly the mucosal and luminal content of EGF compared with that measured in animals with an intact stomach. The luminal and mucosal EGF contents gradually increased with consecutive ASA insults compared to values in rats exposed to a single dose of ASA. The mucosal content of EGF 


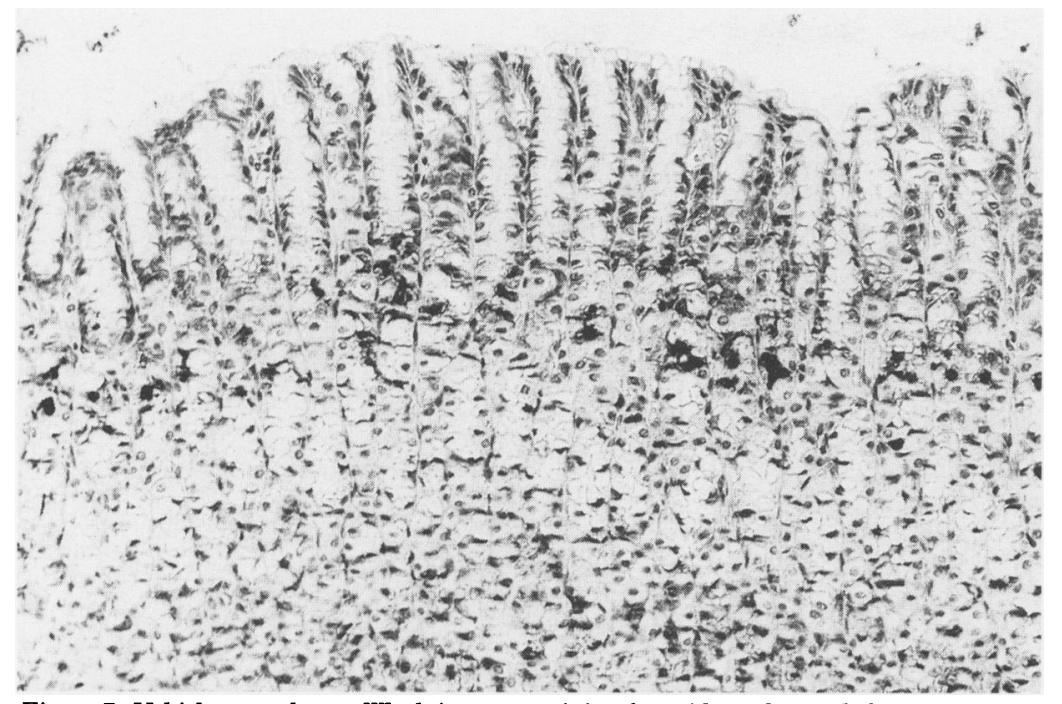

Figure 7: Vehicle treated rats. Weak immunostaining for epidermal growth factor receptor is present in some mucus neck occasional parietal cells (original magnification $\times 200$ ).

TABLE III Luminal and mucosal immunoreactivity of epidermal growth factor (EGF) and mucosal expression of $E G F$ receptor (EGFr) in rats after the first dose (day 0) of acidified $A S A$ and following each of the four doses applied during next four days of treatment with ASA with or without challenge with strong irritants. Mean (SEM) of six rats per group

\begin{tabular}{|c|c|c|c|}
\hline & $\begin{array}{l}\text { Luminal } \\
E G F \\
(n g / m l)\end{array}$ & $\begin{array}{l}\text { Mucosal } \\
E G F \\
\text { (ng/g) }\end{array}$ & $\begin{array}{l}\text { Expression } \\
\text { of EGFr } \\
(\%)\end{array}$ \\
\hline $\begin{array}{l}\text { Intact gastric mucosa } \\
\text { ASA: }\end{array}$ & $31(5)$ & $49(4)$ & $13 \cdot 5(2)$ \\
\hline $\begin{array}{l}\text { Day } 0 \\
\text { Day } 1 \\
\text { Day } 2 \\
\text { Day } 3 \\
\text { Day } 4\end{array}$ & $\begin{array}{l}45(7) \\
52(6) \\
92(18)^{\star} \\
148(31)^{\star} \\
182(13)^{\star}\end{array}$ & $\begin{array}{l}58(6) \\
65(12) \\
94(8)^{\star} \\
155(19)^{\star} \\
210(12)^{\star}\end{array}$ & $\begin{array}{l}2 \cdot 1(0 \cdot 2) \\
24(4)^{\star} \\
42(6)^{\star} \\
58(7)^{\star} \\
65(8 \cdot 5)^{\star}\end{array}$ \\
\hline \multicolumn{4}{|c|}{ Irritant in unadapted stomach: } \\
\hline $\begin{array}{l}100 \% \text { Ethanol } \\
200 \mathrm{mM} \text { taurocholate } \\
25 \% \mathrm{NaCl} \\
\text { ASA } \\
\text { WRS }\end{array}$ & $\begin{array}{l}56(8) \\
48(6) \\
89(9)^{\star} \\
45(3) \\
86(5)^{\star}\end{array}$ & $\begin{array}{l}64(6) \\
52(4) \\
59(6) \\
56(5) \\
98(9)^{\star}\end{array}$ & $\begin{array}{l}3 \cdot 8(0 \cdot 9) \\
4 \cdot 4(1 \cdot 3) \\
8 \cdot 3(2 \cdot 5) \\
3 \cdot 5(0 \cdot 5) \\
7 \cdot 2(1 \cdot 4)\end{array}$ \\
\hline \multicolumn{4}{|c|}{ Irritant in ASA adapted stomach: } \\
\hline $\begin{array}{l}100 \% \text { Ethanol } \\
200 \mathrm{mM} \text { taurocholate } \\
25 \% \mathrm{NaCl} \\
\text { ASA } \\
\text { WRS }\end{array}$ & $\begin{array}{l}390(25) \dagger \\
340(18) \dagger \\
409(28) \dagger \\
190(15) \dagger \\
184(12) \dagger\end{array}$ & $\begin{array}{l}150(9) \dagger \\
160(12) \dagger \\
175(15) \dagger \\
213(22) \dagger \\
180(17) \dagger\end{array}$ & $\begin{array}{l}45 \cdot 2(5 \cdot 1) \\
49 \cdot 6(6 \cdot 2) \\
70 \cdot 2(8 \cdot 5) \\
69 \cdot 4(7 \cdot 5) \\
61 \cdot 8(7 \cdot 2)\end{array}$ \\
\hline
\end{tabular}

*Indicates significant $(\mathrm{p}<0.05)$ change compared to the first exposure to ASA.tIndicates significant change $(p<0.05)$ compared to exposure of irritant to unadapted stomach. WRS=water restraint stress.

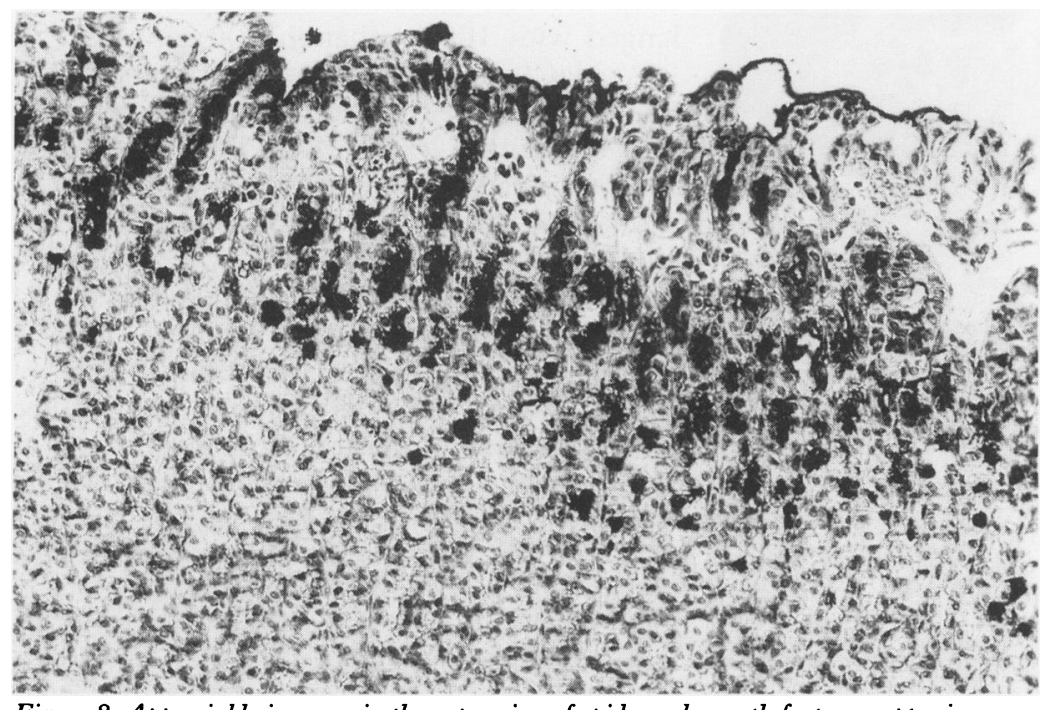

Figure 8: Appreciable increase in the expression of epidermal growth factor receptor is present in mucus neck cells and surface epithelial cells of regeneration area of the oxyntic mucosa. remained unchanged in unadapted rats challenged with $100 \%$ ethanol, $200 \mathrm{mM}$ TC, or $25 \% \mathrm{NaCl}$ but it reached significantly higher values in rats exposed to repetitive ASA insults. In rats adapted to ASA and challenged with acidified ASA, $100 \%$ ethanol, $200 \mathrm{mM}$ TC, $25 \% \mathrm{NaCl}$, or stress, there was a significant increase in the luminal and mucosal contents of EGF compared with values in respective unadapted rats exposed to each of the irritants.

\section{Discussion}

The present study confirms our previous observations ${ }^{17} 18$ that the rat stomach has the ability to resist further damage despite continuous exposure to acidified ASA. This adaptation is accompanied by restoration of the gastric blood flow, increased expression of EGF and its receptors, and an increase in the luminal EGF contents. Furthermore, the gastric mucosa adapted to ASA is remarkably resistant to the injury caused by necrotising substances such as absolute ethanol, $200 \mathrm{mM}$ $\mathrm{TC}, 25 \% \mathrm{NaCl}$, or by stress. This reduction in the formation of acute gastric lesions in the ASA adapted stomach in response to challenge with noxious agents is accompanied by gastric hyperaemia, a noticeable increase in the mucosal expression of EGF and its receptor, and an impressive increase in mucosal cell regeneration.

Adaptation describes the phenomenon in which visible gastric mucosal injury lessens or resolves completely despite continued insults of injurious agents such as ASA. We have reported that the gastric mucosa adapts to repeated $A_{S A}{ }^{1718}$ or stress ${ }^{12}$ insults and that this is accompanied by gastric hyperaemia, probably mediated by sensory nerves but not by endogenous prostaglandin, at least in the case of adaptation to ASA. ${ }^{17} 18$ In this study, the first exposure to ASA reduced gastric blood flow considerably but upon adaptation to injury by repeated exposure to ASA, the gastric blood flow tended to return to a value similar to that recorded in the intact mucosa. Mucosal generation of prostaglandin $\mathrm{E}_{2}$ was inhibited with the first dose of ASA and remained suppressed throughout adaptation to ASA and subsequent insults by various irritants, confirming that endogenous prostaglandins are not required for the development of this adaptation, the accompanying gastric hyperaemia, or increased mucosal defence against various topical irritants.

The role of prostaglandins in the short term adaptation of the gastric mucosa to damage by various ulcerogens was originally examined by Robert et al. ${ }^{22} 23$ They first showed that oral administration of mild irritants such as $10-20 \%$ ethanol, $5 \% \mathrm{NaCl}$, or $5 \mathrm{mM}$ TC prevented the massive mucosal damage caused by necrotising agents such as $100 \%$ ethanol, $25 \%$ $\mathrm{NaCl}, 80 \mathrm{mM}$ TC, $0.6 \mathrm{~N} \mathrm{HCl}$, or $0.2 \mathrm{~N} \mathrm{NaCl}$. This effect resembled that induced by exogenous application of prostaglandins ${ }^{22-24}$ and has been called adaptive cytoprotection. Moreover, mild irritants were found to increase the mucosal capability to generate 
prostaglandin, while reducing the formation of acute gastric lesions caused by necrotising agents. $^{22-24}$ The involvement of endogenous prostaglandin in this short lived (about one to two hours) adaptation of the stomach was supported by the demonstration that both the gastroprotection and the increase in mucosal generation of prostaglandins in response to a mild irritant was reversed by the suppression of prostaglandin biosynthesis with indomethacin. ${ }^{22-24}$ It is of interest that adaptive cytoprotection induced by one type of mild irritant such as $20 \%$ ethanol resulted in an increased mucosal tolerance to the injury caused by a high concentration of not only the same type of irritant - that is, $100 \%$ ethanol (homocytoprotection) but also of other strong irritants such as $25 \% \mathrm{NaCl}$, strong acid or strong base (cross protection). ${ }^{23}$ The cross adaptation of mild irritants was further confirmed by showing that mild stress induced in rats by short restraint of animals in the cage, attenuated the formation of gastric lesions caused by severe stress as well as by the exposure of the mucosa to $40 \%$ ethanol. ${ }^{25}$ The seven day pretreatment with mild stress or a low concentration of ethanol prevented the formation of mucosal lesions in rats subjected to strong restraint stress or absolute ethanol. ${ }^{25}$ In another study, Uramoto et al ${ }^{26}$ have shown that the gastric mucosa of restraint loaded rats exerted a greater resistance to the damaging action of absolute ethanol. In their study, the protective effect of mild stress was significantly mitigated by vagotomy or indomethacin suggesting that vagal influences or endogenous prostaglandin, or both, could be involved in the mechanism of this cross adaptation.

It is of interest that cross adaptation to mild irritants has also been demonstrated in vitro, using cultured surface epithelium treated with strong ulcerogens. ${ }^{27}$ This protective action of mild irritants was abolished by indomethacin reinforcing the crucial role of endogenous prostaglandins in the mediation of this adaptive response in vitro. ${ }^{27}$

The major finding of our present study is the demonstration for the first time that mucosa adapted to repetitive insults of ASA is more resistant to the damage induced by other necrotising agents such as $100 \%$ ethanol, $200 \mathrm{mM} \mathrm{TC}$, or $25 \% \mathrm{NaCl}$. Adaptation to ASA occurred despite complete suppression of prostaglandin generation in the gastric mucosa, and yet the adapted gastric mucosa was less susceptible to the damage caused by topical ulcerogens or stress. This is in keeping with the study of Shorrock et al, ${ }^{28}$ carried out in man, which showed that the adaptation to indomethacin does not depend upon the local generation of prostaglandins but is accompanied by an increase in the gastric blood flow.

It is interesting that the mucosa adapted to ASA, which by itself is an acid dependent ulcerogen, showed enhanced resistance to damage by both acid dependent irritants (for example, stress, TC, or ASA) and acid independent irritants (for example, $100 \%$ ethanol or hypertonic $\mathrm{NaCl}$ ).

Enhanced blood flow ${ }^{17}$ and increased cell proliferation ${ }^{182930}$ were recently proposed as the major mechanisms responsible for the adaptation to ASA but the role of growth factors, ${ }^{31} 32$ in particular an overexpression of EGF and its receptors, in this adaptation was limited to stress induced lesions. Our detailed histological assessment showed that the first exposure to ASA leads to widespread damage of the surface epithelium and deep necrotic lesions extending into the gastric glands. This first exposure to ASA caused extensive desquamation of mucosal surface and deep necrosis but both these changes were reduced during the development of adaptation to the ulcerogen and, in the same time, a marked mucosal regeneration was observed. This regeneration was remarkably impressive after repeated ASA insults as shown by the elongation of gland neck and foveolar areas lined with cuboidal regenerative epithelium. The mechanism of this process is not clear but the finding that regenerative changes occurred after single exposure to ASA applied in damaging dose indicates that initial mucosal damage is necessary for the rapid restitution and is later followed by the cell proliferation most evident in the regenerative zone. This is in keeping with original observation of Schmidt et al ${ }^{33}$ that adaptive protection requires direct contact and initial surface cell damage and can not be demonstrated in intact, undamaged gastric mucosa. Interestingly, gastric adaptation initiated by the first exposure of the gastric mucosa to an irritant is not limited to ulcerogenic action of salicylate type of NSAID such as aspirin because, as reported recently, ${ }^{34}$ rats dosed repeatedly with a non-salicylate NSAID agent, such as diclofenac, also showed progressive reduction in macroscopic and deep necrotic damage. Further evidence that adaptation to ASA is non-specific was provided by Wallace et $a l^{35}$ by showing that with chronic ASA administration, the gastric mucosa becomes significantly more resistant to damage induced by the new challenge not only with ASA but also with other NSAID such as indomethacin or naproxen.

Similarly to ASA in our study, the initial exposure to $100 \%$ ethanol, $25 \% \mathrm{NaCl}$, or $200 \mathrm{mM}$ TC caused widespread damage to the surface epithelium and deep necrotic lesions accompanied by a fall in the gastric blood flow and the absence of the expression of receptors for EGF. However, rats adapted to ASA and then challenged with $100 \%$ ethanol, $200 \mathrm{mM}$ $\mathrm{TC}$, or $25 \% \mathrm{NaCl}$ showed a marked reduction in ulcerogenesis, and this was accompanied by a significant rise in gastric blood flow and by expression of EGF and its receptors to an extent similar to that observed in rats adapted to ASA. This suggests that the enhanced production of EGF and augmentation of specific receptor sites for this peptide may contribute to the adaptation and to the enhanced resistance of the gastric mucosa to injury caused by necrotising agents. The regeneration of gastric mucosa during gastric adaptation to ASA is probably mediated predominantly by EGF because in addition to the rise in the mucosal expression of EGF and its receptor, 
the luminal contents of immunoreactive EGF were significantly increased during adaptation and remained raised in ASA adapted rats challenged with strong irritants. Salivary EGF could play a part in the process of mucosal repair and adaptation because, as previously observed, the formation of submandibulary EGF was significantly increased after the exposure of gastric mucosa to acid dependent or acid independent ulcerogens. ${ }^{36}$ Indeed, in our present study the luminal content of EGF was markedly increased after adaptation to ASA and after challenge with strong irritants, indicating that EGF of salivary origin may interact with specific receptors over expressed in the mucosa and this may be essential for the regeneration observed during adaptation to these ulcerogens. This notion is supported by our recent observation ${ }^{12}$ that removal of salivary glands abolished gastric adaptation to stress and reduced that of $\mathrm{ASA}^{1218}$ and this was accompanied by a significant decrease in the luminal contents of EGF. Since damaged gastric mucosa is capable of secreting EGF from the novel cell lineages, ${ }^{37}$ it is likely, that gastric luminal EGF in the ASA adapted stomach originates from local gastric production rather than from the excessive release by salivary glands. That the changes in EGF and EGFr could be, at least partly, epiphenomena related to excessive mucosal regeneration and may not be directly responsible for the resistance of the epithelium to further damage has not been excluded.

Our previous study ${ }^{38-40}$ using specific receptor binding assay showed that normal gastric mucosa expresses receptors for TGF $\alpha$ and EGF, and that both peptides were equally effective in protection against the damage induced by strong irritants. That an augmented local expression of TGF $\alpha$ which shares a common high affinity receptor with EGF 4041 and is greatly increased after acute mucosal damage with hyperosmolar solution, ${ }^{41}$ could also participate in the gastric adaptation to ASA and enhanced resistance of the ASA adapted mucosa against the damage by strong irritant has not been excluded. Our present results show, however, that although normal mucosa exhibits relatively higher expression of TGF $\alpha$ than of EGF, the ASA adapted mucosa exhibits an enhanced expression only of EGF but shows no further increase in TGF $\alpha$ expression. It is reasonable, therefore, to assume that EGF rather than $\mathrm{TGF} \alpha$ plays a crucial role in the gastric adaptation to ASA and in the subsequent increase in the mucosal tolerance to necrotising substances.

1 McCarthy DM. Nonsteroidal antiinflammatory druginduced ulcers: management by traditional therapies. induced ulcers: management by

2 Konturek SJ, Konturek JW. Gastric adaptation: basic and clinical aspects. Digestion 1994; 55: 131-8.

3 St John DJB, Yeomans ND, McDermott FT, De Boer WGRM. Adaptation of the gastric mucosa to repeated administration of aspirin in the rat. Am $\mathcal{F}$ Dig Dis 1973; 18: $881-6$.

4 Graham DJ, Smith JL, Dobbs SM. Gastric adaptation occurs with aspirin administration in man. Dig Dis Sci 1983; 28: 1-6.

5 Graham DJ, Smith JL, Spjut HJ, Torres E. Gastric adaptation. Studies in humans during continuous aspirin administration. Gastroenterology 1988; 95: 327-33.
6 Olivero JJ, Graham DJ. Gastric adaptation to nonsteroidal anti-inflammatory drugs in man. Scand 7 Gastroenterol anti-inflammatory drugs

7 Shorrock CJ, Prescott RJ, Rees WDW. The effect of indomethacin on gastroduodenal morphology and mucosal pH gradient in the healthy human stomach. Gastroenterology 1990; 99: 334-9.

8 Ivey KJ, Tarnawski A, Stachura J, Werner H, Mach T, Burks $M$. The induction of gastric mucosal tolerance to alcohol by chronic administration. F Lab Clin Med 1980; 96: $928-32$.

9 Lacy ER. Gastric mucosal resistance to a repeated ethanol insult. Scand $\mathcal{f}$ Gastroenterol 1985; 20 (suppl 1): 63-72.

10 Robert A, Lancaster C, Olafson AS, Zhang W. Gastric adaptation to repeated administration of a necrotizing agent. In: Garner A, O'Brien PB, eds. Mechanism of injury protection and repair of the upper gastrointestinal tract. Chichester: Wiley, 1991: 357-70.

11 Lacy ER, Cowart KS, Hund P. Effects of chronic superficial injury in the rat gastric mucosa. Gastroenterology 1992; 103: 1179-91.

12 Konturek SJ, Brzozowski T, Majka J, Drozdowicz D, Stachura J. Adaptation of the mucosa to stress. Role of prostaglandins and epidermal growth factor. Scand $\mathfrak{f}$ Grostaglandins and epidermal growth factor.

13 Wallace IL. Prostaglandins, NSAID and cytoprotection. Gastroenterol Clin North Am 1992; 21: 631-41.

14 Fries JF, Williams CA, Bloch DA, Michel BA. Nonsteroidal anti-inflammatory drug-association gastropathy: incidence and risk factor models. Am $\mathcal{F}$ Med 1991; 91: 213-22.

15 Wallace $\mathrm{JL}$. Non-steroidal anti-inflammatory drug gastropathy and cytoprotection: pathogenesis and mechanisms re-examined. Scand f Gastroenterol 1992; 192: 3-8.

16 Wallace JL, Keenan CM, Granger DN. Gastric ulceration induced by nonsteroidal anti-inflammatory drugs is a neutrophil-dependent process. Am $\mathcal{F}$ Physiol 1980; 259: 462-7.

17 Konturek SJ, Brzozowski T, Stachura J, Majka J. Role of neutrophils and mucosal blood flow in gastric adaptation to aspirin. Eur f Pharmacol 1994; 253: 107-14.

18 Konturek SJ, Brzozowski T, Stachura J, Dembinski A, Majka J. Role of gastric blood flow, neutrophil infiltration and mucosal cell proliferation in gastric adaptation to aspirin in rats. Gut 1994; 35: 1189-96.

19 Konturek PK, Brzozowski T, Drozdowciz D, Krzyzek E, Garlicki J, Majka J, et al. Nocloprost, a unique prostaglandin $\mathrm{E}_{2}$ analog with local gastroprotective and ulcer healing activity. Eur $\mathcal{A}$ Pharmacol 1991; 195: 347-53.

20 Thomas DM, Nasim MM, Gullick WJ, Alison Mr. Immunoreactivity of transforming growth factor alpha in the normal and adult gastrointestinal tract. Gut 1992; 33: the norm

21 Jankowski J, McMenemin R, Yu C, Hopwood KG, Wormsley KG. Proliferating cell nuclear antigen in esophageal diseases; correlation with transforming growth factor alpha expression. Gut 1992; 33: 587-91.

22 Robert A, Nezamis JE, Lancaster C, Dabis JP, Field S, Hanchar AJ. Mild irritants prevent gastric necrosis through 'adaptive cytoprotection' mediated by prostaglandins. Am $\mathcal{F}$ Physiol 1983; 245: 113-21.

23 Robert A. Cytoprotection by prostaglandins. Gastroenterology 1979; 77: 761-7.

24 Konturek SJ, Brzozowski T, Piastucki I, Radecki T, Dembinski A, Dembinska-Kiec A. Role of locally gemerated prostaglandins in adaptive gastric cytoprotecgenerated prostaglandins in adaptive
tion. Dig Dis Sci 1982; 27: 967-71.

25 Glavin G, Lockhart LK, Rockman GE, Hall AM, Kiernan KM. Evidence of 'cross-stressed' - induced adaptive gastric cytoprotection. Life Sci 1987; 41: 2223-7.

26 Uramoto $\mathrm{H}$, Ohno $\mathrm{T}$, Ishthara $\mathrm{T}$. Gastric mucosal protection induced by restraint and water-immersion stress in rats. Ipn $\mathcal{F}$ Pharmacol 1990; 54: 287-98.

27 Arakawa T, Nakamura A, Fukuda T, Higuchi K, Nakamura $\mathrm{H}$, Kobayashi $\mathbf{K}$. In vitro adaptive cytoprotection in gastric cells isolated from rat stomach. $\mathcal{F}$ Clin Gastroenterol 1990; 12 (suppl 1): 32-8.

28 Shorrock CJ, Rees WD. Mucosal adaptation to indomethacin induced gastric damage in man - studies on morphology, blood flow, and prostaglandin $\mathrm{E}_{2}$ metamorphology, blood flow, and

29 Eastwood GJ, Quimby GE. Effect of chronic aspirin ingestion on epithelial proliferation in rat funds, antrum and duodenum. Gastroenterology 1982; 82: 852-6.

30 Levi S, Goodlad RA, Lee CY, Walport MJ, Wright NA, Hodgson HJ. Effects of nonsteroidal anti-inflammatory drugs and misoprostol on gastroduodenal epithelial proliferation in arthritis. Gastroenterology 1992; 102: 1605-11.

31 Konturek SJ, Brzozowski T, Konturek PK, Majka J, Dembinski A. Role of salivary glands and epidermal growth factor (EGF) in gastric secretion and mucosal integrity in rats exposed to stress. Regul Pept 1991; 32: integrity

32 Konturek SJ, Brzozowski T, Majka J, Dembinski A, alpha and epidermal growth factor in protection and alpha and epidermal growth factor in protection and
healing of gastric mucosal injury. Scand $\mathcal{f}$ Gastroenterol

33 Schmidt KL, Smith GS, Miller TA. Microscopic correlates of adaptive cytoprotection in an ethanol injury model. Histol Hisopathol 19 89; 4: 105-15.

34 Skeljo MV, Giraud AS, Yeomans ND. Adaptation of rat gastric mucosa to repeated doses of non-salicylate nonsteroidal anti-inflammatory drugs. $\mathcal{f}$ Gastroenterol-Hepatol 1992; 7: 586-90. 
35 Wallace JL, McKnight GW. Gastric adaptation to aspirin (ASA) is non-specific and prostaglandin-independent.

36 Gysin B, Moller RK, Otten U, Fischli AE. Epidermal growth factor content of submandibular glands is increased in rats with experimentally induced gastric lesions. Scand f Gastroenterol 1988; 23: 665-71.

37 Wright NA, Pike C, Elia G. Induction of a novel epidermal growth factor secreting cell lineage by mucosal ulceration in human gastrointestinal stem cells. Nature 1990; 343: 82-5.

38 Brzozowski T, Konturek SJ, Majka J, Dembiński A Drozdowicz D. Epidermal growth factor, polyamines and prostaglandins in healing of stress-induced gastric lesions in rats. Dig Dis Sci 1993; 38: 276-83.
39 Brzozowski T, Majka J, Konturek SJ, Bielański W, Slomiany BL, Garner A. Gastroprotective activity and receptor expression of transforming growth factor alpha, epidermal growth factor and basic fibroblast growth factor. Eur $\mathcal{f}$ Gastroenterol Hepatol 1994; 6: 337-43.

40 Bielański WJ, Keogh JP, Wang SL, Lin J, Konturek SJ, Slomiany A, Slomiany BL. Transforming growth factor alpha binds to the epidermal growth factor receptor in gastric mucosa. Biochemistry International 1991; 25:

41 Polk WH, Dempsey PJ, Russell WE, Brown PJ, Beanchamp RD, Bernard JA, Coffey RJ. Increased production of transforming growth factor alpha following acute gastric injury. Gastroenterology 1992; 102: 1467-74. 